Profesor de español en la Ferris State University, en el estado de Michigan de Estados Unidos, es autor de varios libros y artículos sobre la poesía hispanoamericana contemporánea, particularmente la mexicana y la paraguaya. Así mismo ha residido y enseñado en el Perú, en México y en España. En 1997 le otorgaron una beca

\title{
DOS EXTREMOS DE LA POESÍA PARAGUAYA: CARLOS VILLAGRA MARSAL Y JOAQUÍN MORALES
}

Fulbright para dictar clases de la poesía posmoderna hispanoamericana en la Universidad Católica de Asunción, y para llevar a cabo investigaciones sobre la poesía paraguaya. A base de esta experiencia, Haladyna actualmente prepara una antología sobre la poesía paraguaya.

RONALD HALADYNA

El presente de la poesía paraguaya contemporánea ofrece una rica variedad de tendencias. Entre éstas, encontramos en un extremo la poesía vitalista y seguidora de los esquemas menos vanguardistas del siglo $\mathrm{XX}$ de Carlos Villagra Marsal, y en el contrario el rupturismo y la innovación trascendental que representa Joaquín Morales entre otros poetas coetáneos. Así, podemos situar dos obras como El júbilo difícil de Villagra y Postales desde Bizancio de Morales, como vértices extremos del amplio espectro de la poesía paraguaya actual.

\section{EL JÚBILO DIFÍCIL DE CARLOS VI- LLAGRA MARSAL}

AQUEL HUMO
Quemazón azul
de octubre
veladura repujada
estás más cerca
de mi palabra
que del horizonte viejo.

Pilar de humareda capital soy tu trasunto una refracción apenas de tu empeño: brasa dispuesta rojizo lenguaje codicioso luego morosa vehemencia niebla seca ciego ascenso $y$ al fin disgregación en el ensimismado firmamento. (32)
Según algunos teóricos postmodernistas, el futuro de la poesía se encuentra irremediablemente en entredicho puesto que todo lo que se tenía que decir ya se ha dicho y que los poetas actuales - plenamente conscientes de su largo e ilustre ascendiente literario y, sin embargo, ansiosos de expresarse con originalidad - no pueden aspirar a más que asimilar la tradición y trascenderla con sus toques personales (léase «estilo»). Esta solemne y lúgubre perspectiva no toma en cuenta que a todo poeta se le apodera la irrefrenable pasión por inmortalizar sus vivencias en palabras, independientemente de lo que digan los teóricos. El júbilo difícil (1995) de Carlos Villagra Marsal se revela como otro argumento convincente en contra del supuesto fin de la poesía.

Si aceptamos que la metáfora se ha destacado en la poesía como la condición sine qua non, como la piedra fundacional en cualquier construcción poética - como sugiere Eduardo Milán (6) - el edificio poético de Villagra Marsal ha sido construido con cimientos sólidos y hermosos. Aunque El júbilo difícil se empeña en desempolvar todos aquellos aspectos poéticos que hoy comúnmente han sido descartados pero que antaño se consideraban elementales - métrica, rima, ritmo, elocuencia, brevedad, gracia, sutileza, así como temas y lenguaje decorosos - la metáfora sobresale por su ubicuidad y la imaginativa atención a su acabado. De especial interés es la combinación de varias metáforas consecutivas en serie, como se aprecia en el poema ya citado, «Aquel humo». Metáforas de apenas dos o
Dos extremos de la poesía paraguaya: Carlos Villagra Marsal y Joaquín Morales RONALD HALADYNA 


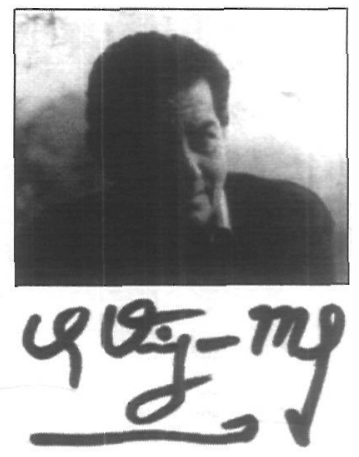

Carlos Villagra. tres palabras renombran y giran alrededor de una sola imagen: «quemazón azul», "veladura repujada», «humareda capital» «brasa dispuesta», «rojizo lenguaje codicioso», «morosa vehemencia», «niebla seca», y «ciego ascenso». Más que diferentes enfoques de una sola realidad, he aquí las distintas perspectivas de un lenguaje virtual o inmanente. Según Thab Hassan la «inmanencia», no debe entenderse con ningún sentido teológico, sino como «la capacidad imaginativa de generalizarse a sí misma en símbolos, intervenir cada vez más en la naturaleza, actuar sobre sí misma a través de sus propias abstracciones y convertirse... en su propio medio ambiente» (traducción mía, 93).

El ambiente verbal se demuestra repetidamente en El júbilo difícil tanto para seres vivos como para las cosas y los fenómenos naturales. La luna: «el cachorro de luna»; «flameante carnicero nuevo»; «vástago de león azul»; «creciente animal» (35). El paisaje: «invitación trascordada / promesa de sesgado cumplimiento» [...] Oh desmemoriado / paraje resuelto / oh contemplado aroma / oh denominador del tiempo / oh distancia curtida / oh digitación de cielo / oh vasija de la intemperie / oh cambiante paroxismo desierto» (40). La lluvia: "pausa esmerilada, / ciudadela instantánea, / muralla levantada [...] goteadora [...] garúa entrefina, / cerrazón, / soledad movediza [...] agua interior» (42-43). Este denso tejido metafórico genera una serie de imágenes que recalca el dominio que el poeta necesita tener sobre el lenguaje. El crítico Charles Altieri piensa que el buen poeta interpreta una experiencia en lugar de describirla. Así mismo, al reconocer que la experiencia consiste en palabras y no en ideas, «las mejores líricas evitan 'la discursividad ensayística' de los ensayistas en verso... y muestran la potencia del lenguaje de expresar lo que habíamos pensado inexpresable» (traducción mía, 5).

En la sección «Ciertos pájaros» se encuentran veinte poemas dedicados a pájaros peculiares al trópico paraguayo, todos identificados por sus nombres en guaraní. Este virtual catálogo ornitológico rinde tributo y, en efecto, exotiza especies que seguramente habitaban lo que hoy son las crecientes zonas urbanas del Paraguay. Aunque las descripciónes físicas de las especies - colores y forma del plumaje, pico, ojos y alas - están des- lumbrantemente logradas, también se agregan otras más inusitadas como sus acciones características: la trayectoria de su vuelo, el tono de su canción, sus hábitos culinarios, sus métodos de seducción o de engaño, su horario de actividad y de reposo y sus dones específicos, como sea el caso para cada uno. Estos retratos cuidadosamente pintados confieren una personalidad inconfundible a cada especie, las antropomorfizan, sobre todo cuando el poeta se dirige a todos los pájaros de «vos», sugiriendo hermandad con los amigos volantes así como una meticulosa e íntima observación directa o indirecta de su vida.

Pero hay otra hermandad en juego aquí: la que une textos de poesía y de las ciencias naturales; un fenómeno que ha acrecentado en años recientes y que tal vez tiene que ver con la revolución de la informática, la disipación de los linderos entre las disciplinas y la consecuente interdisciplinaridad, o tal vez la creciente concesión de que toda escritura es potencialmente material poético. En varios poemas sobre los pájaros y en uno sobre las frutas («Jakarati'a») las citas usadas como epígrafes provienen de enciclopedias o de libros especializados y sirven en una capacidad aclaratoria, como si fuera para sentar una necesaria base de observación científica desde la cual la imaginación del poeta puede despegarse en vuelos de imaginación verbal. Es así que en poemas como «Doble loor del suruku'a», «Se yergue de amores desiertos la calandria» y «Preñado reposo augusto del taguato apyratî» las citas, como material extratextual en efecto se incorporan a lo textual, es decir, se integran como una parte indispensable de los poemas. La complementaridad parece ser el propósito de juntar textos científicos con textos poéticos, pero cabe señalar que la oposición de los textos nos obliga a reflexionar sobre el notable contraste en el uso del lenguaje para fines ostensiblemente distintos. El texto científico procura ser directo, escueto, exacto, claro y poco ambiguo con la intención de facilitar una representación de la esencia de una realidad. Este uso del lenguaje netamente pragmático cuenta con la supuesta transparencia del lenguaje y la consecuente claridad y eficacia de comunicación. Por el contrario, el texto poético no propone tanto la recreación del objeto, sino el uso del objeto como un pretexto para el recreo del lenguaje. La densidad meta- 
fórica, la inusitada sintaxis, el vasto vocabulario y el consistente esmero en la métrica y la rima: todo está diseñado para llamar la atención al lenguaje como un fin en sí y sólo secundariamente como un instrumento de comunicación. La ironía de la poesía como ésta es que no sólo se logra una representación eficaz, sino también se hace de una manera más divertida e inolvidable que cualquier texto científico.

En contraste con aquellos pájaros conocidos por la belleza de su plumaje o la singularidad de su canto, se ofrece una perspectiva distinta con las aves rapaces y de pillaje; pero la descripción de éstos se destaca por intencionalmente ignorar precisamente su característica más notable: su agresión. La sutileza predomina aquí: se menciona de paso su naturaleza agresiva y su potencia de devastación, pero se elude lo que potencialmente sería en un texto lo más dramático y explotable de su identidad biológica para concentrar en otros rasgos relacionados a su instinto mortífero. Las aves rapaces, conocidas por la velocidad de su vuelo y la manera en que agarran su presa a toda velocidad. Pero estos poemas evitan lo dramático y las expectativas más comunes al limitarse a sugerir sólo la violencia del acto mismo, dejando la parte más cruenta a la imaginación del lector. La voz poética menciona las víctimas del saqueo pero abrevia la descripción del momento más decisivo de su voracidad en poemas como, por ejemplo, «tukâ hovy»: «... sobrevienes y saqueas y te vas» (68); en «aka'ê hovy»: «turbas nido tras nido, más curioso que osado / y voraz más que pícaro» (74). Para el halcón «morotî», el poeta pinta un ambiente de inminencia: "y el asalto presumo: / el precipicio de tu incendio blanco...» (84); y para el «taguato apyratî» menciona su presa, pero omite la inevitable sangre: «Ejecutante sobrio del venado, / imparcial asesino del enjuto / tigrillo y del lagarto novelero» (86). La ferocidad del «ñakurutû hû» se sintetiza en sólo dos breves versos: «tomador / de carne oculta y lunas minuciosas» y "ávido sargento / y capataz del aniquilamiento» otra vez sólo sugiriendo su actividad nocturna sin representarla gráficamente. Pero el poema que mejor ilustra el arte de soslayar el aspecto más sangriento y más dramático de las aves rapaces es "Acometida del taguato'i»:

\author{
Con el silencio violento \\ de tu penacho azulejo \\ hincas y ejerces un viejo \\ embate oblicuo en el viento; \\ un choque, un destello hambriento \\ bastan; la sangre despena \\ tu sed, el aire refrena \\ su ardor o su sobresalto \\ y un vago plumón en algo \\ declara la muerte ajena. (71)
}

Se suele comentar que los medios de comunicación masiva en esta época han confundido el libre ejercicio de la expresión con el atrevimiento de decir o mostrar cualquier cosa (intima, violenta, monstruosa) de la manera más prosaica y obvia para bajarse comercialmente a los gustos públicos más accesibles y lo que más ha sufrido es la sutileza artística. Ahora con versos como los de «La acometida del taguato'i» tenemos el polo opuesto y se le obliga a uno a reflexionar sobre la identidad del posible público lector de poesía como ésta. Tanto su elegancia de estilo, como su sofisticado vocabulario y su complejidad métrica van a quedar años luz de distancia del alcance de todos aquellos lectores que no tengan una considerable base literaria.

Pero hay otro peligro respecto a un público potencialmente mucho más grande. Entre los lectores que no sepan guaraní, algunos sin duda van a quedar fascinados por la incursión de exóticos vocablos guaraníes en los poemas de El júbilo difícil. Estas palabras agregan una rica dimensión cultural a una poesía patentemente regionalista que se deleita en elogiar la flora y la fauna peculiares a este país. Además sirven - conscientemente o no- para oponerse a la creciente homogeneización de la cultura occidental y para recordarnos de nuevo que el bilingualismo y el biculturalismo también son aspectos insoslayables de la realidad paraguaya. Sin la ayuda de un ñe' eryru, tal vez los vocablos guaraníes provocarán en otros lectores una sensación de incompletez en su lectura que lastimosamente restará su aprecio por esta poesía. Dadas las circunstancias geográficas, culturales, lingüísticas, temáticas y estéticas, la inclusión de estos vocablos no sólo es apropiada, sino imprescindible porque la palabra justa es determinada por el específico efecto deseado y el contexto reinante. Reemplazar "ypekû sayju», por ejemplo, con «pájaro-carpintero-amarillo» resultaría

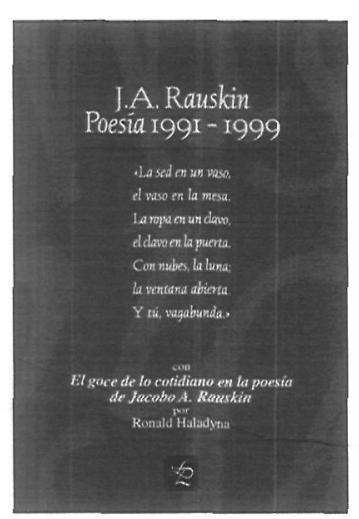

Rauskin. Poriada.
Dos extremos de la poesía paraguaya: Carlos Villagra Marsal y Joaquín Morales RONALD HALADYNA 


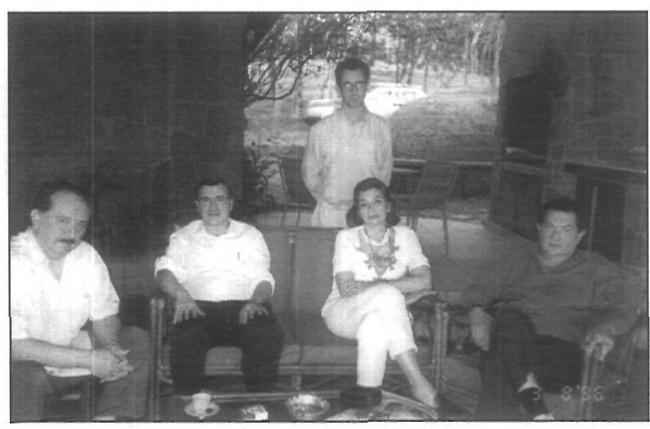

Última Altura. Helio Vera, José Vicente Peiró, Ana Mª Carron y Carlos Villagra Marsal (sentados) y Guido Rodríguez Alcalá (de pie). (Foto: José Vicente Peiró).

1

«El que me entienda debe arrojar la escalera luego que por ella haya escalado. Él debe superar esas frases y luego verá correctamente el mundo». Traducción de Helena Rauskin.
Dos extremos de la poesía paraguaya: Carlos Villagra Marsal y Joaquín Morales RONAID HAI ADYNA contextualmente falso y estéticamente torpe. Aunque los títulos de los poemas dedicados a los pájaros y las frutas han sido acertadamente traducidos al castellano por el editor Raúl Amaral, muchos otros vocablos en guaraní necesitan semejantes traducciones. Ahora que se habla cada vez más de la inclusión de la poesía paraguaya en la «universalidad»-según una apreciación del mismo Amaral en su prólogo a El júbilo difícil (5) - siempre convendría en los futuros libros que tengan palabras en guaraní la inclusión de un glosario de equivalencias guaraní-castellano al final del libro, algo así como hacía el novelista peruano, José María Arguedas, para su frecuente uso de vocabulario quechua.

Hasta llegar a la penúltima sección de El júbilo difícil, no se concede nada al lado desagradable de la vida; no existe el menor interés ni el más leve indicio de lo feo, lo descompuesto, lo repulsivo, lo corrupto, lo injusto o lo irremediable en el reino biológico o mineral. Pero con la sección «Cantata del pueblo y sus banderas torrenciales», lo que aparenta prestarse para otro motivo de júbilo - la caída de la dictadura de Stroessner- pronto se convierte en una triste reflexión de la tiranía y en eso estriba la perfecta adecuación del título de este poemario. Los recuerdos amargos intervienen en todos estos poemas: «Asunción, ciudad vacía, / cansada de tanta peste...» (142); «a pesar de los golpes en la cara, / el grito no se esconde ni se mancha» (143); «los hombres que propone la luz adolescente / salvarán su camino del miedo y las basura» (144); «al joven impacto / del brazo sincero, / caerán las prisiones, /huirá el carcelero» (145); «huesos de Aurelio y Francisco, / dueños por fin de un rozado / arriba de las cosechas / y más allá del arado» (147). El júbilo por el derrocamiento de la dictadura se vuelve particularmente difícil cuando se toma conciencia de que la transición a la democracia no impacta sustancialmente la vida de los pobres:

\section{ESTE PAN EXIGIDO II \\ El cielo sucesivo \\ agrava el desamparo}

\begin{abstract}
y la antigua fatiga
hierve despacio;

condición del obrero

uncido a su trabajo:

en la mesa vacía,

se sirve llanto.
\end{abstract}

\author{
Mensualero del hambre, \\ albañil por un rato, \\ nocturno embarcadizo, \\ y ferroviario, \\ de pie, contra el que humilla \\ espaldas y salarios, \\ para honrar la esperanza \\ de un pan más alto.
}

\section{para Saúl Ibargoyen Islas}

La producción poética de El júbilo difícil abarca precisamente los años antes y después de la transición a la democracia; lo que resulta intrigante es el ordenamiento (nada cronológico) de los poemas que sitúa «Cantata del pueblo y sus banderas torrenciales» como la penúltima sección del libro. Salvo este agridulce «júbilo difícil», el suntuoso poemario se dedica exclusivamente a desvelar la belleza del mundo - los cielos y los fenómenos meteorológicos, los pájaros y las frutas regionales, los familiares y «poemas sobrevivientes» $-\mathrm{y}$ la celebra con todos los medios a su disposición: la esmerada selección de un vocabulario altilocuente; una rima cuidadosamente variada y consistentemente presente; una métrica impecable; una metaforización imaginativa y sutil; hasta la cubierta del libro - color terroso y deleite táctil-y las páginas de color crema con letra terrosa. Todo se junta en El júbilo difícil para integrar una majestuosa representación de la belleza de este mundo en una época cuando parece que cada vez más se nos extravia la capacidad de maravilla.

\section{UN BUZÓN LLENO DE SORPRESAS: POSTALES DE BIZANCIO DE JOAQUÍN MORALES}

¿Cuántos libros de poesía en lengua castellana empiezan con un epigrama del Tractatus Logico-Philosophicus (1921) del filósofo austriaco Ludwig Wittgenstein y en alemán nada menos? Personalmente no tengo la menor idea, pero me aventuraría a adivinar que muy pocos. Encontré uno hace unos días en Posta- 
les de Bizancio (1984) del paraguayo Joaquín Morales ${ }^{1}$. Aunque la selección de un título apropiado para una obra literaria convencionalmente debería sugerir la esencia de la temática sin pecar de obviedad, el uso de un epigrama no siempre obedece los mismos criterios, razón por la cual esta elección de Morales me intrigó aún más después de leer este interesante libro.

Muchos años después de la publicación del Tractatus, Wittgenstein sugiere en su Investigaciones filosóficas (1953) que todas las palabras (significantes lingüísticos) están integradas en «juegos de lenguaje». Cada «juego» lingüístico es definido por un sistema de reglas que gobiernan la manera en la cual se usan las palabras dentro de ese contexto. En este sentido el lenguaje se parece a un juego - como el ajedrez- que tiene reglas que determinan cómo se pueden mover las piezas. Lo importante de esta teoría es que nuestros juegos modifican la manera en que experimentamos el mundo y la idea convenció tanto a teóricos como a escritores de este siglo a abandonar la perspectiva realista en favor de una perspectiva no realista o constructivista. Los constructivistas subrayan que es el lenguaje que da acceso al mundo; lo que nosotros llamamos el «mundo verdadero» no es más que una creación social siempre en evolución².

En las dos últimas décadas uno no se extraña al encontrar que los poetas no sólo tienen conocimientos de la filosofía moderna y de la teoría crítica sino que también incorporan en su poesía los mismos estilos y temáticas teóricas que absorben en sus lecturas. Por lo tanto hemos visto en años recientes evidencia de estas influencias en la obra de argentinos como Roberto Jurroz y Alberto Girri, en la del mexicano David Huerta y ahora en Postales de Bizancio.

Esta obra de Morales es, en gran parte, una poesía crítica. Aunque mucha poesía expresa implícita o explícitamente su propia arte poética, la poesía crítica dicta en forma concentrada la agonía de la insuficiencia de la potencia de las palabras para transmitir las ideas o del temor de no poder decir nada en absoluto ${ }^{3}$. Encontramos a lo largo de los 53 poemas de Postales de Bizancio varias referencias al uso de las palabras y del lenguaje que demuestran una constante preocupación y un asiduo cuestionamiento no sólo de la adecuación de las palabras para expresar la realidad, sino también de la posibilidad de una percepción sensorial del «mundo verdadero", de la formulación de ideas, de la veracidad de la memoria y de la re-creación de experiencias, recuerdos y conceptos en palabras. En esencia, se nos plantean en Postales de Bizancio muchas cuestiones axiales de las cuales se han ocupado los filósofos, teóricos y comentaristas durante gran parte de este siglo.

Tal vez su «Arte poética 1» resulte tan buen lugar como cualquiera donde empezar:

$$
\begin{aligned}
& \text { Palabras de papel, } \\
& \text { palabras de viento. } \\
& \text { Se van, se pierden, } \\
& \text { se olvidan, } \\
& \text { no sirven para nada } \\
& \text { y no dan de comer. }
\end{aligned}
$$

Pero como lectores conscientes enfrentamos un dilema: ¿Debemos tomar estas palabras en serio si el poeta mismo no parece darles importancia a ellas? Mi respuesta es un enfático «sí» porque el poema está expresando - con un razonamiento nada postmoderno- un posible paradigma postmoderno, uno que refleja un cuestionamiento fundamental del logos que ha sido formulado desde el siglo pasado por Friedrich Nietzsche y en éste por Ferdinand de Saussure, Hans Georg Gadamer, Martin Heiddeger, Jacques Derrida y por cierto el ya citado Wittgenstein.

Pero también es posible contestar que «no» porque en realidad está expresando algo - con estas palabras - que parece muy cierto.

Postales de Bizancio es una poesía a punto de ser postmoderna. Varios poemas en este libro definitivamente no son nada postmodernos; pero en el arranque de otros se nota una tendencia hacia un lirismo coloquial de situaciones y tonos aptos para todo público. Pero en estos poemas la placidez del ambiente cambia repentinamente con la intromisión de lo que se parecería una sorpresiva falta de buenos modales. Es así que el lector experimenta una sacudida en poemas como «Li Po, muerto» en el cual entre las disculpas y el arrepentimiento del poeta ante el espíritu del célebre poeta chino cambia de opinión y promete emborracharse (40); o en «Inminencia de la casa» donde «volver a casa significa... el viejo placer de orinar en el jardín» (46); o en «Apuntes para una épica urbana» (66-67) en el cual el poeta confiesa que en su adolescencia se mas-
2

Stanley J. Grenz, A Primer on Postmodernism (Grand Rapids, Michigan: William B. Eerdmans, 1996) $112-114$.

3

"Poesía crítica,» un término acuñado por Ocłavio Paz para aquella poesía que que expresa escepticismo hacia el lenguaje y que cuestiona su propia construcción. Ver Thorpe Running, The Critical Poem, (Lewisburg, Pennsylvania: Bucknell University Press, 1996), 11.
Dos extremos de la poesía paraguaya: Carlos Villagra Marsal y Joaquín Morales RONALD HALADYNA 

G.E.M. Anscombe. (Frankfurt am Main: Suhrkamp Verlag, 1969), citado en Gerd Brand, Los textos fundamentales de Ludwig Wittgenstein. (Madrid: Alianza Universidad, 1975, 97-98).
Dos extremos de la poesía paraguaya: Carlos Villagra Marsal y Joaquín Morales RONALD HALADYNA turbaba y se enamoró de una tía solterona; o como vemos en "Ratones en el piano», donde utiliza un raticida para asegurar el éxito de un concierto del «lirismo de Liszt» (68). La inclusión de actos escandalosos irrumpe así en los momentos menos esperados sugiriendo que en el ámbito de los poemas, tal como ocurre en la vida, todos los registros de comportamiento pueden presentarse sin la menor advertencia. Estas sorpresas exigen al lector su constante vigilia porque algo sorpresivo puede ocurrir a la vuelta de cualquier esquina, sentando así la base de un importante consejo del postmodernismo: no tomar nada por sentado.

Otros poemas se concentran en los mismos temas que han ocupado la atención de los postmodernistas en los últimos treinta años: cuestiones relacionadas a la aprehensión visual, la percepción y el olvido, la metapoesía, la fenomenología, un cuestionamiento de la teoría de la correspondencia y temas nietzscheanos. La incorporación de estos tópicos en sí es sugerente de un texto postmoderno por las ideas radicales que proponen con respecto, por ejemplo, al lenguaje. En el poema «Contra las palabras» el poeta se arremete contra la arbitraria asignación de significado a las palabras, un tema central de pensadores desde Nietzsche hasta Derrida:

palabras, meras palabras,
fraguado polvo de ruido
$\ldots$...
Y esta confusión, sinceramente,
me preocupa:
pero la ordenación de las cosas
es insulto a cada una
si el pegarles rótulos
y barajarlos con cuidado
nos deja en las vitrinas un olor rancio,
sequedad de pergamino (18).

Tanto Friedrich Nietzsche como Ferdinand de Saussure han dejado sus huellas aquí. Aquél por su insistencia en respetar la infinita riqueza y variedad de la realidad, una realidad que sufre injustificables reducciones cuando se intenta representarla con palabras. Éste por su desvinculación de significante y significado; un ataque frontal contra la teoría de la correspondencia entre la palabra y la realidad que propone representar.

Nietzsche y Wittgenstein están dondequiera en esta poesía que toca lo fundamental del Tractatus - la relación entre realidad y lenguaje - como se evidencia en estos fragmentos de «Proyecto de fin de semana»:

Un mundo sin porqués ni desdecuándos,
ni evidencia para ningún nombre
ni nombres para lo que no tiene evidencias...
...
Todo enunciado
una generalización no comprobable,
una aseveración presuntuosa,
una apuesta para diversión
de dioses aburridos
(apenas habitantes de enciclopedias):
en que no haya término de acción ninguna
ni precedentes, ni tendencias,
ni reminiscencia en que apoyar
la sospecha de haber estado allí antes... (32-33)

Si bien Nietzsche apachurró la validez de los conceptos usados por los filósofos para establecer las «verdades» del mundo moderno, Wittgenstein posteriormente pisoteó la idea de que el uso del lenguaje surge por un encuentro trascendental del sujeto con un mundo objetivo. La oposición aquí a las generalizaciones y los conceptos; esta desconfianza en el lenguaje y en la confianza tradicional en su capacidad de re-presentar la realidad; todo refleja la filosofía y el tono de Nietzsche. El filósofo alemán no sólo negaba el afán del Occidente de crear conceptos con palabras; también creía que el lenguaje era la realidad y que todo lenguaje está al servicio de los poderosos de las sociedades que querían ejercer con él su voluntad de dominar. Son ideas seminales que siguen ejerciendo una enorme influencia en el pensamiento occidental del siglo XX y que han hecho eco en la literatura, aquí en la poesía de Joaquín Morales.

Unos años antes del Tractatus, Wittgenstein advierte en el Tägebucher que

«... comprendemos el mundo como sistema. Puedo reducir la descripción del mundo a una forma unitaria, colocando sobre él una 'red' como, por ejemplo, la descripción del mundo que hizo Newton. No hay que confundir esto con la comprensión»4.

He dicho que esta poesía es casi postmoderna porque parece estar en un proceso de transición. Como ocurre en la poesía del poeta mexicano David Huerta, las frecuentes incursiones de la problemática del lenguaje - central en el discurso teórico de los últimos vein- 
te años - en la misma poesía de Morales incide en una paradoja sin salida: la aparente inutilidad del lenguaje sólo puede ser comunicada con el mismo lenguaje. Comunicada, pero no demostrada todavía en la poesía de Joaquín Morales que sigue desenrollándose de una manera tan clara y convincentemente que parece desmentir sus propias afirmaciones.

La presencia de Wittgenstein (el de Investigaciones filosóficas) es notable especialmente en poemas posteriores que no iban a aparecer hasta la publicación de Muestra de poesía (Arandurã, 1995) como si el poeta quisiera poner en práctica la idea wittgensteiniana sobre el lenguaje como un juego. En unos fragmentos del poema «Hurras a Bizancio» ${ }^{5}$, encontramos un virtual paradigma del lenguaje en juego:

metahistorieta hiperculta post $(\mathrm{u})$ moderna semicomics megakitsch polidramática politraumática paraliteraria transretorizante intertextual antiparnasiana hipertrófica antipirética epigástrica protonocturna versificada profusamente anotada cuasi encantamiento y ensalmo celebratorio medio kachiäi de los decires cultos y de nación, glosas floriculturales y musicales ortopedias de robusta poética bien temperada al uso de los antiguos maestros de capilla flamencos y borgoñones y grecoguaraníticos puesta en materia poética según la celebrada y gloriosa tectónica de la Casa Torta y el literario Mbaipy Parnasiano regados por abundante Zeitgeist de la mejor cosecha, id est Secunda Reconstructio... (45)

Según Wittgenstein, el uso del lenguaje constituye un juego, consistente sólo con las propias reglas establecida para los fines del juego, reglas siempre establecidas por los usuarios del mismo. Este torrentoso caudal de palabras de todo registro de Hurras a Bizancio - satirizando la exagerada sofisticación de los textos de teoría crítica, filosofía, historia y sociología - del «Newspeak» científico adoptado en los círculos humanísticos. No sólo se burla de tipos académicos como nosotros sino que, y más importante, demuestra gráficamente una conclusión fundamental de los filósofos y teóricos del siglo $X X$-algo que no le sorprendería a la gran mayoría de una población ya dolorosamente enterada de los abusos del poder- que las palabras sólo son palabras. Tras las máscaras de los textos de la sofisticación científica o humanística, de la grandilocuencia política, de la cuidadosa selección de «las noticias más importantes» por los medios de la comunicación masiva, las palabras - como diría Wittgenstein - están siempre en juego y los que establecen las reglas del juego - de acuerdo con Nietzsche - siguen ejerciendo su voluntad de dominio.

En un artículo anterior yo había mencionado que la poesía paraguaya sigue siendo dominada por la lírica de la tradición románticasimbolista, una opinión que todavía sostengo. Pero Joaquín Morales está abriendo a machetazos un camino por bosques desconocidos; una poesía interesante por la novedosa perspectiva que aporta; y prometedor porque hay mucho bosque verbal por delante. Con «Hurras a Bizancio» ha empezado a practicar lo que antes sólo presentaba como una posibilidad teórica. Que siga su exploración.

\section{BIBLIOGRAFÍA}

Amaral, Raúl. Prólogo. «La poesía natural y profunda de Carlos Villagra Parsal». El júbilo difícil. Por Carlos Villagra Marsal. Asunción: Don Bosco, 1995.

Altieri, Charles. Self and Sensibility in Contemporary American Poetry. Cambridge, MA: Cambridge UP, 1984.

Hassan, Ihab. The Postmodern Turn: Essays in Postmodern Theory and Culture. Columbus: Ohio State UP, 1987.

Milán, Eduardo. «Roberto Echavarren: Posiciones. El contexto general». Poemas largos. De Roberto Echavarren. Montevideo: Arca, 1989. 5-13.
5

Ver Muestra de poesía (Asunción: Arandurã; Montevideo: Banda Oriental, 1995). 